\title{
AN EVALUATION OF TWO NEW LOCAL ANAESTHETICS FOR MAJOR CONDUCTION BLOCKADE
}

\author{
P. R. BROMAGE, M.B., F.F.A.R.C.S., AND M. GERTEL, M.D.C.M., F.R.C.P. (C) ${ }^{\circ}$
}

THE SUCCESS AND ACCEPTABLITY of conduction blockade in clinical practice depends on the skill of the administrator, and the right drug to do the job. The introduction of the xylidide local anaesthetics by Lofgren in the 1940s represented an enormous advance in the reliability of regional anaesthesia. ${ }^{1}$ However, two areas still remain unsatisfactory from the clinical point of view. These are, first, the long waiting time required between injection and the onset of good surgical anaesthesia, and second, the relatively short duration of the available drugs, which cannot guarantee reliable anaesthesia for longer than about four hours.

Recently two agents have been introduced which appear to go a long way towards meeting both clinical requirements, fast reliable onset and prolonged duration. These are the fast acting carbonated local anaesthetics ${ }^{2,3}$ and the long acting local anaesthetic agent bupivacaine, originally known as LAC-43. ${ }^{4}$ The formulae for these two agents are shown in Figure 1.

\section{$\mathrm{CO}_{2}$-Lidocaine}

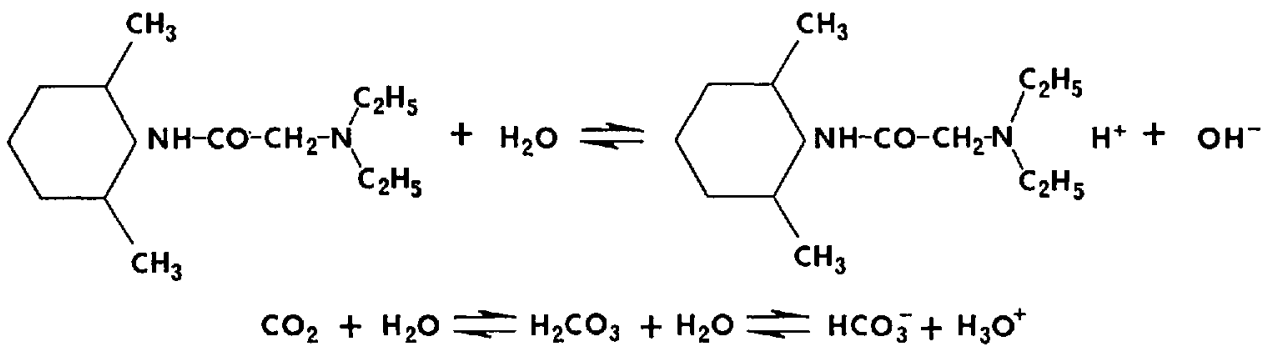

\section{Bupivacaine}<smiles>CCN1CCCCC1C(=O)NC1C(C)CCCC1C</smiles>

\section{Bupivacaine $n=3$ \\ Mepivacaine $n=0$}

Frgure 1. Chemical formulae for carbonated lidocaine and bupivacaine.

'Department of Anaesthesia, Royal Victoria Hospital, and McGill University, Montreal, P.Q. 
This paper will summarize our experiences with these two agents for epidural anaesthesia and supraclavicular brachial blockade in 320 cases. We will place the results in perspective against the capabilities of three other commonly available local anaesthetics. All agents studied had epinephrine freshly added to a concentration of $1: 200,000$.

\section{METHODS}

\section{Epidural anaesthesia}

Comparisons were made with results from previous series using a standardized approach at the second lumbar interspace. ${ }^{5}$ The test groups are outlined in Table I. Latency of onset, intensity of motor blockade, and duration of anaesthesia were compared in the various groups, using criteria previously described. ${ }^{2}$

\section{TABLE I}

Evaluation of $\mathrm{CO}_{2}$-Lidocaine and Bupivacaine $\mathrm{HCl}$ by Epidural Blockade

\begin{tabular}{cc}
\hline $\begin{array}{c}\text { Test solutions } \\
\text { (with } 1 / 200,000 \\
\text { epinephrine) }\end{array}$ & No. of cases \\
\hline $2 \%$ Lidocaine $\mathrm{HCl}$ & 65 \\
$2 \%$ Mepivacaine $\mathrm{HCl}$ & 25 \\
$0.5 \%$ Tetracaine $\mathrm{HCl}$ & 37 \\
$2 \%$ CO & 150 \\
$0.5 \%$ Bupidocaine & 76 \\
Total & 253 \\
\hline
\end{tabular}

\section{Brachial plexus block}

A modification of Kulenkampff's supraclavicular approach was used. Paraesthesiae were sought with a 23 gauge needle, and the solution was injected above the first rib and behind the subclavian artery.

Latency of onset was taken as the time from commencement of injection until cutaneous anaesthesia to pin-prick was established in the entire hand and forearm.

Duration of action was taken as the interval between establishment of complete anaesthesia and the first appearance of pin-prick sensation at any point below the elbow.

The test groups and the volumes of solutions used are outlined in Table II.

TABLE II

Evaluation of $\mathrm{CO}_{2}$-Lidocaine and Bupivacaine by Supraclavicular Brachial Plexus Blockade

\begin{tabular}{lcc}
\hline $\begin{array}{c}\text { Test solutions } \\
\text { (with 1/200,000 } \\
\text { epinephrine) }\end{array}$ & $\begin{array}{c}\text { Volume } \\
(\mathrm{ml})\end{array}$ & No. of cases \\
\hline $1 \%$ Lidocaine $\mathrm{HCl}$ & 50 & 26 \\
$1 \%$ Mepivacaine $\mathrm{HCl}$ & 50 & 25 \\
$1 \% \mathrm{CO}_{2}$-Lidocaine & 50 & 26 \\
$2 \% \mathrm{CO}_{2}$-Lidocaine & 25 & 26 \\
$0.25 \%$ Bupivacaine & 50 & 28 \\
$1 \% \mathrm{CO}_{2}$ Lidocaine and & 30 & 10 \\
$0.25 \%$ Bupivacaine $\mathrm{HCl})$ & & 140 \\
Total & & \\
\hline
\end{tabular}




\section{RESULTS}

\section{Epidural analgesia}

Onset. Mean latency profiles were constructed from the spread of cutaneous anaesthesia in each group, using sensation to pin-prick as the criterion. Figure 2 shows the mean latency times for the test solutions. It can be seen that the orthodox hydrochloride solutions take a considerable time for complete blockade, particularly in segments $\mathrm{L}-5$ and s-1. Carbonated lidocaine has the fastest onset, (about 10 minutes) and the latency is about 30 per cent faster than its orthodox counterpart, the hydrochloride salt. Bupivacaine in 0.5 per cent concentration is considerably slower, with an onset time comparable to 0.5 per cent tetracaine.

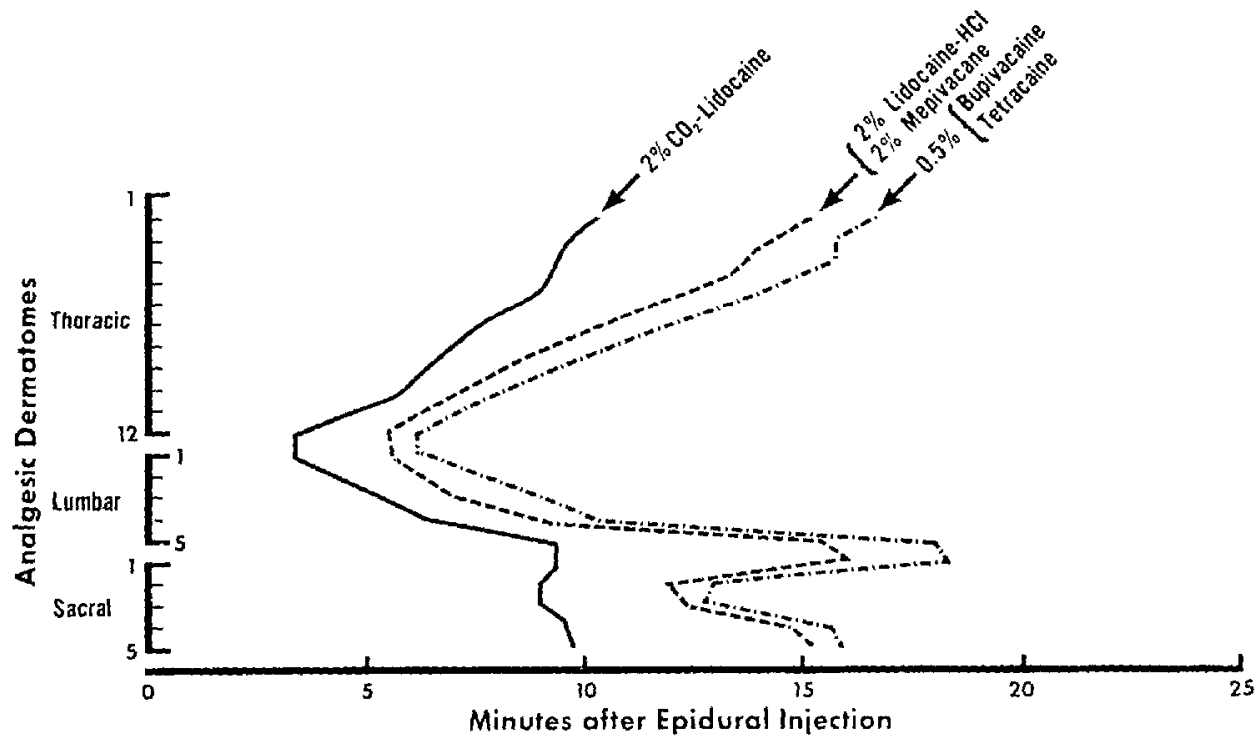

Frgure 2. Onset of epidural blockade. Mean latency profiles for 2 per cent $\mathrm{CO}_{2}$-lidacaine, 2 per cent lidocaine hydrochloride, 2 per cent mepivacaine, 0.5 per cent tetracaine, and 0.5 per cent bupivacaine.

Motor block. The quality of motor blockade is summarized in Table III. It can be seen that carbonated lidocaine produces the most intense degree of motor block ( 51.5 per cent), while 0.5 per cent bupivacaine produces the least degree ( 28.9 per cent).

Duration. The mean durations for the various test solutions in epidural analgesia are shown in Figure 3. Although bupivacaine has the longest duration (200

TABLE III

Epidural Blockade : INTENSITy of Motor Blockade

\begin{tabular}{lc}
\hline Test solution & \% Motor block \\
\hline $2 \%$ Lidocaine $\mathrm{HCl}$ & 36.3 \\
$2 \%$ Mepivacaine $\mathrm{HCl}$ & 35.0 \\
$0.5 \%$ Tetracaine $\mathrm{HCl}$ & 46.4 \\
$2 \%$ CO2-Lidocaine & 51.5 \\
$0.5 \%$ Bupivacaine $\mathrm{HCl}$ & 28.9 \\
\hline
\end{tabular}




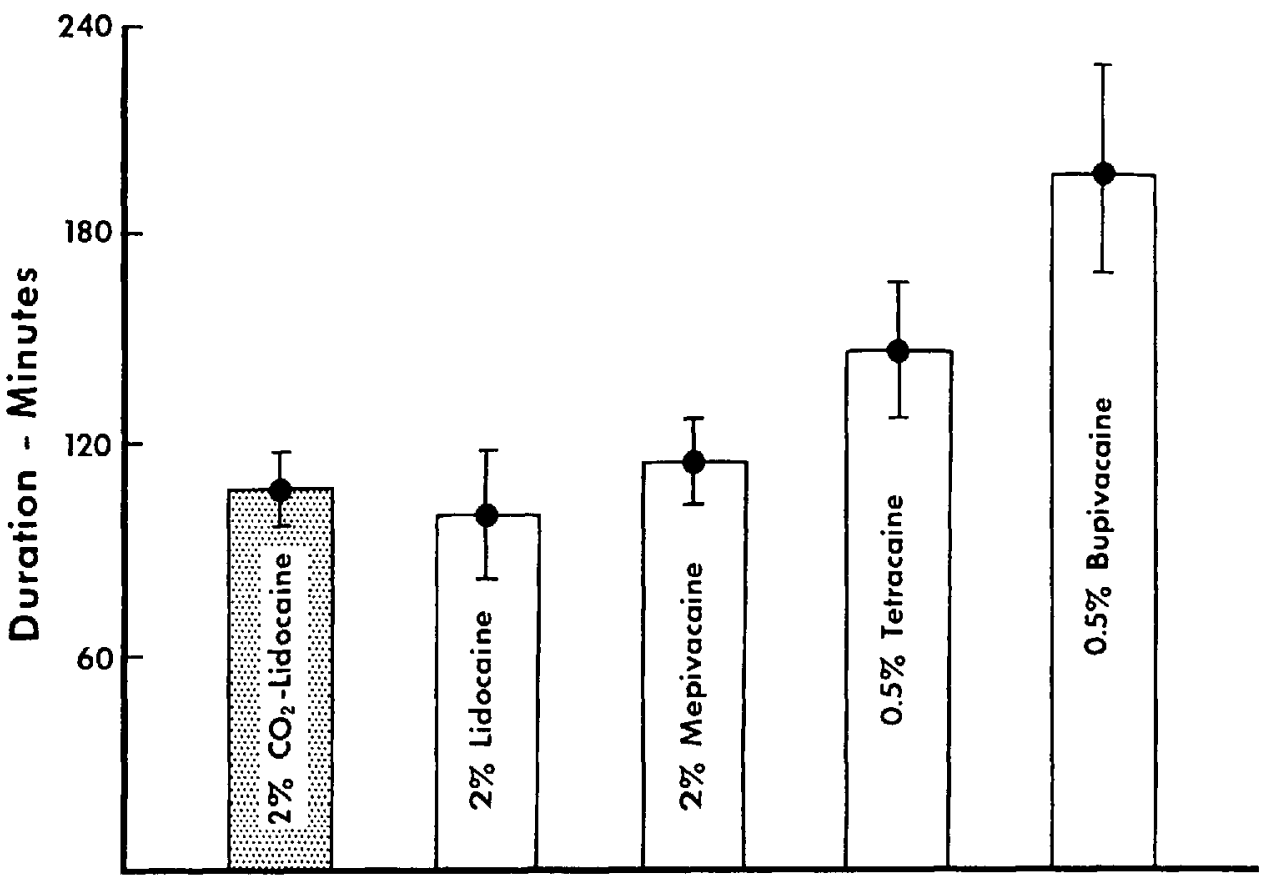

Figure 3. Duration of epidural analgesia, means and standard deviations for 2 per cent $\mathrm{CO}_{2}$-lidocaine, 2 per cent lidocaine hydrochloride, 2 per cent mepivacaine, 0.5 per cent tetracaine, and 0.5 per cent bupivacaine.

minutes), there is not a dramatic difference in duration between the shortest and the longest acting agents, and they differ only by a factor of two.

Brachial plexus block. Figure 4 is a scattergram showing the latency of onset for complete anaesthesia of the hand and forearm for 1 per cent and 2 per cent $\mathrm{CO}_{2}$ lidocaine and 0.25 per cent bupivacaine compared with 1 per cent lidocaine hydrochloride and 1 per cent mepivacaine hydrochloride. It can be seen that the results vary quite widely, both for each drug and between drugs. The shortest duration and least variability is found with the $\mathrm{CO}_{2}$-lidocaine solutions, while the widest variation and the longest mean latency is found with bupivacaine. The differences between the two extremes are very striking. From the statistical data in Table IV we can see that with 2 per cent $\mathrm{CO}_{2}$-lidocaine intense blockade is complete in 90 per cent of cases within 12 minutes. With bupivacaine it takes 35 minutes, or nearly three times as long, to be sure of complete analgesia in 90 per cent of cases. In the bupivacaine series three patients out of 28 (i.e. 9 per cent) had only patchy incomplete analgesia after an interval of 35 minutes, and those three cases were excluded from the data in Table IV.

Figure 5 shows the duration of action of brachial plexus blockade. The distribution of duration for the five solutions reflects their ranking of onset time in the previous figure. The $\mathrm{CO}_{2}$ solutions have the shortest action, with a mean of about $2 \%$ hours, followed by lidocaine hydrochloride with a mean of $3 \frac{1}{4}$ hours, then mepivacaine with a mean of 4 hours. Mepivacaine is a useful "middle distance" drug and its mean duration of 4 hours gives adequate operating time for most procedures on the hand and arm. Finally we come to bupivacaine, with an 


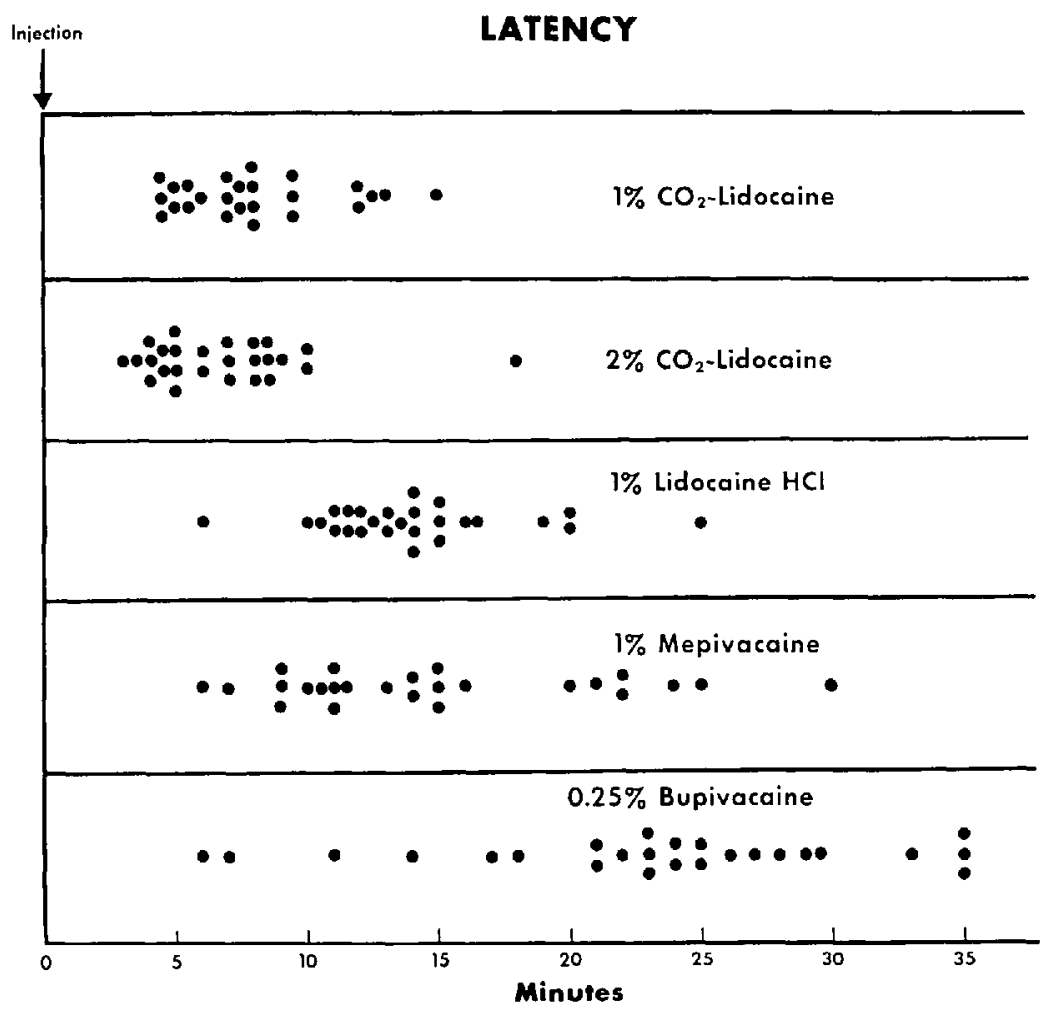

Frgune 4. Onset of brachial plexus blockade. Latency for 1 per cent and 2 per cent $\mathrm{CO}_{2}$-lidocaine, 1 per cent lidocaine hydrochloride, 1 per cent mepivacaine, and 0.25 per cent bupivacaine.

TABLE IV

Supraclavicular Brachial Plexus Blockade: Onset and Duration

\begin{tabular}{|c|c|c|c|c|c|c|c|}
\hline \multirow{2}{*}{$\begin{array}{l}\text { Analgesic solution } \\
\text { (with } 1 / 200,000 \\
\text { epinephrine) }\end{array}$} & \multirow{2}{*}{$\begin{array}{l}\text { Vol. } \\
(\mathrm{ml})\end{array}$} & \multicolumn{3}{|c|}{$\begin{array}{l}\text { Latency for complete } \\
\text { blockade (mins) }\end{array}$} & \multicolumn{3}{|c|}{$\begin{array}{c}\text { Duration at } 40 \\
\text { years of age } \\
\text { (mins) }\end{array}$} \\
\hline & & $\mathrm{N}$ & mean & SD & $\mathbf{N}$ & mean & SD \\
\hline 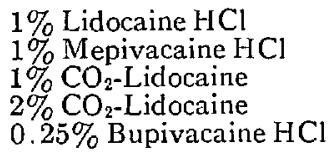 & $\begin{array}{l}50 \\
50 \\
50 \\
25 \\
56\end{array}$ & $\begin{array}{l}26 \\
25 \\
26 \\
26 \\
25\end{array}$ & $\begin{array}{r}14.04 \\
14.84 \\
8.06 \\
6.81 \\
23.26\end{array}$ & $\begin{array}{l}3.83 \\
6.22 \\
2.94 \\
3.08 \\
7.93\end{array}$ & $\begin{array}{l}24 \\
24 \\
18 \\
21 \\
21\end{array}$ & $\begin{array}{l}195 \\
245 \\
178 \\
154 \\
613\end{array}$ & $\begin{array}{r}26.3 \\
26.8 \\
36.4 \\
25.4 \\
126\end{array}$ \\
\hline
\end{tabular}

N.B. In any group $90 \%$ of all cases will fall within the limits of the mean \pm SD $\times 1.68$.

TABLE V

Supraclavicular Brachial Plexus Blockade

\begin{tabular}{|c|c|c|c|}
\hline \multicolumn{4}{|c|}{$\begin{array}{c}1 \% \mathrm{CO}_{2} \text {-lidocaine and } 0.25 \% \text { bupivacaine } \mathrm{HCl} \text { with } \\
1 / 200,000 \text { epinephrine }\end{array}$} \\
\hline $\mathbf{N}$ & $\begin{array}{l}\text { vol } \\
(\mathrm{ml})\end{array}$ & $\begin{array}{c}\text { average time to } \\
\text { complete black } \\
\text { (mins) }\end{array}$ & $\begin{array}{l}\text { duration } \\
\text { (mins) }\end{array}$ \\
\hline 10 & 30 & 7.5 & 445 \\
\hline
\end{tabular}




\section{DURATION}

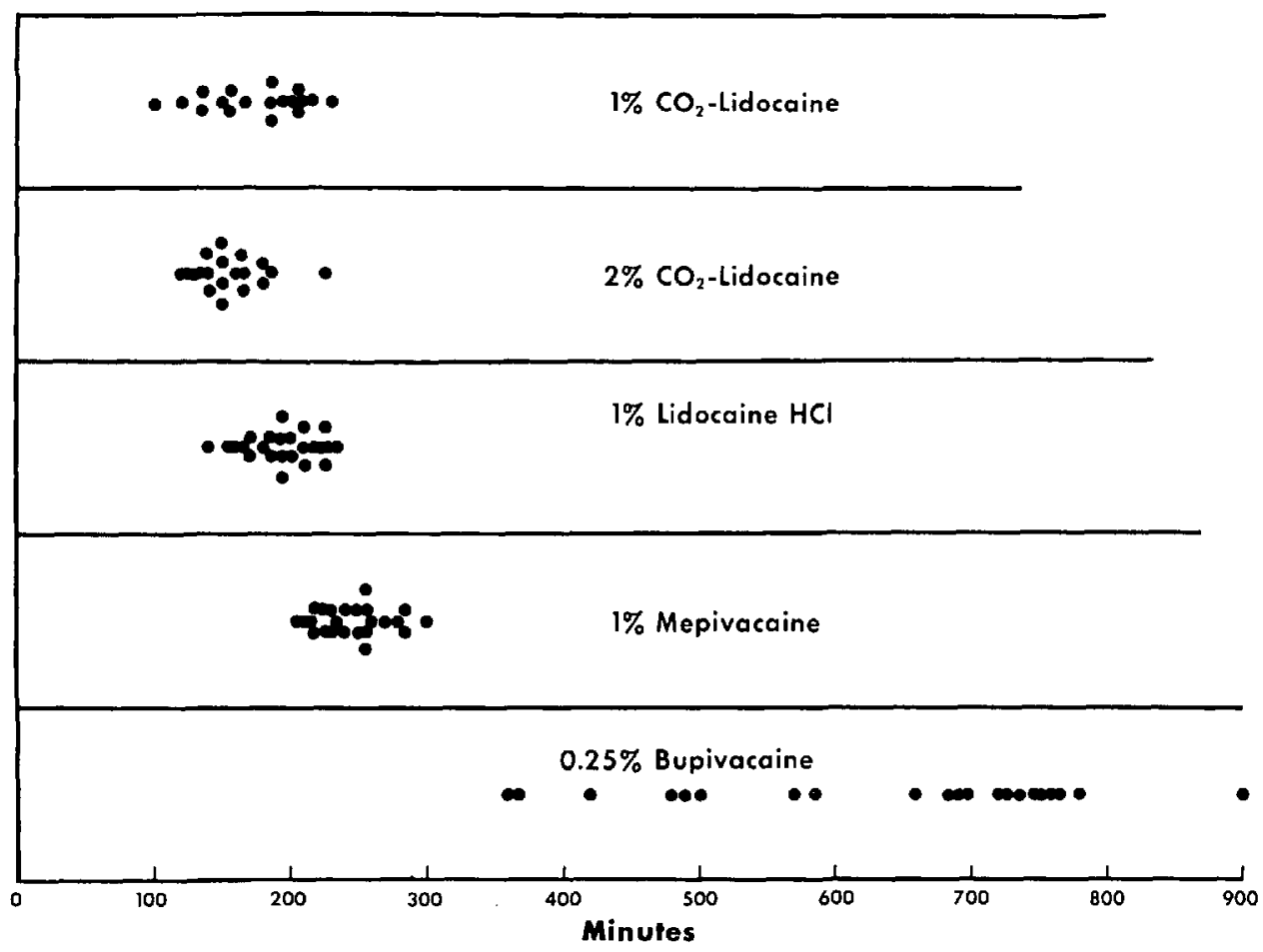

Figure 5. Duration of brachial plexus blockade with 1 per cent and 2 per cent $\mathrm{CO}_{2}$-lidocaine, 1 per cent lidocaine hydrochloride, 1 per cent mepivacaine, and 0.25 per cent bupivacaine.

extremely long but variable duration of between 6 and 15 hours, with a mean of 10\% hours. This very prolonged blockade provides an excellent type of postoperative analgesia. But one point must be borne in mind: after 8 hours or so most patients begin to become agitated and anxious that their deadened arm will remain paralysed forever, and so they must be fully informed about the enduring qualities of the drug before the operation, and it should be pointed out to them that this particular drug will keep them completely comfortable for longer than any other agent presently available.

\section{Discussion}

We now have two striking new agents for major conduction blockade, both well tested and documented in animals and man, and no fault has been found in them. Each has unique and highly desirable properties, which are polarized in opposite directions. One, the carbonated solution, is very quick acting, powerful, and reliable, but of rather short duration. The other, bupivacaine, is very slow to take effect and is less intense in the quality of its blockade, but is extremely long acting in peripheral nerve blocks.' Both of these agents have been under investigation for more than six years either in this country or abroad, and yet, thanks to the food and drug regulations at the time of writing, the ordinary 
anaesthetist is still unable to obtain either drug for routine use on this continent. It is a sad reflection on our sclerosing bureaucracy that we have slipped so far from the lead of international pharmaceutical advances. Now we trail deep in the wake of our European colleagues, unable to bring the proven benefits of well tried drugs to our clinical practice and our patients.

The principle of carbonating local anaesthetic bases was first devised by $\mathrm{Mr}$. George Nordström of Astra Development Laboratories in 1963, and this novel approach has opened up an entirely new order of capabilities to existing local anaesthetic drugs. To date, the process has been applied to prilocaine and lidocaine, and with each agent the onset time has been shortened by 30 per cent, and the intensity of motor blockade has been increased by 30 per cent. ${ }^{2,3}$ In our present series the latency of brachial plexus anaesthesia has also been dramatically shortened, and the waiting time for complete anaesthesia of the hand and forearm has been almost halved by using carbonated lidocaine. The ensuing analgesia is more profound and more evenly distributed throughout the branches of the brachial plexus than after other local anaesthetics, and the clinical reliability is greater than with any other drug we have tested.

Clearly, the process of carbonation could be applied to any local anaesthetic base, and perhaps this manufacturing technique might be used for some of the slower but longer acting drugs that will undoubtedly be developed in the future.

Bupivacaine has some very interesting properties which appear to be related to its distribution in extraneural tissue. It is relatively short acting in the subarachnoid space, ${ }^{6}$ slightly longer acting in the epidural space, ${ }^{7}$ and very long acting in peripheral nerve blocks. ${ }^{4}$ Thus its duration seems to be related to the thickness of extraneural tissues around the target nerves and therefore its prolonged action would seem to be a function of its distribution (and perhaps binding) in extraneural tissues rather than in the nerves themselves and their myelin sheaths. Secondly, it produces relatively little motor block compared to other agents. ${ }^{7,8}$ Lastly, bupivacaine is very slow in onset.

Here surely is an opportunity for the pharmaceutical industry to use the tools at its disposal to create an agent with the clinical capabilities we require, that is, fast onset, great reliability, and very prolonged action. We would suggest they take bupivacaine, or some similar ultra-long acting agent, and carbonate it, in order to obtain all of these clinically desirable qualities in one agent.

We have tried to see how this principle of carbonating long acting drugs might work in practice by using mixtures of carbonated lidocaine with bupivacaine. Table $V$ summarizes our results with a small series of brachial plexus blocks using $30 \mathrm{ml}$ of a mixture of 1 per cent lidocaine and 0.25 per cent bupivacaine. It can be seen that a fast mean latency of $7 \%$ minutes is combined with a mean duration of about $7 \% 2$ hours.

The practice of mixing local anaesthetic drugs is not ideal, since the toxicity of the two agents is additive. Nevertheless the dosage used in this small series was within acceptable toxic limits, and the results suggest that we are approaching the ideal situation of a very fast onset and a very prolonged duration. We still need a single drug to produce these two desirable effects, and the results of carbonating ultra-long acting agents will be awaited with interest. 


\section{SUMMARY}

Two new local anaesthetic agents, one fast acting (lidocaine hydrocarbonate) and one long acting (bupivacaine hydrochloride), have been compared with the established agents lidocaine hydrochloride and mepivacaine hydrochloride for epidural anaesthesia and supraclavicular brachial plexus block in 320 patients.

Carbonated lidocaine was very quick acting and produced surgical anaesthesia 30 per cent faster than any of the other agents tested in both epidural and brachial plexus blockade, and its quality of anaesthesia was the most intense and reliable. Bupivacaine had the slowest onset and it produced less intense motor blockade.

Duration of action was about the same for the two lidocaine salts, but mepivacaine lasted about 20 per cent longer, while bupivacaine lasted about 90 per cent longer than lidocaine in epidural analgesia. In brachial plexus anaesthesia all the agents lasted longer than in epidural analgesia: lidocaine and mepivacaine lasted twice as long, but bupivacaine lasted three times as long. The average duration of brachial plexus anaesthesia with bupivacaine was more than ten hours, but the individual results were widely scattered, and the standard deviation exceeded two hours.

A mixture containing 1 per cent carbonated lidocaine and 0.25 per cent bupivacaine gave the best clinical compromise in brachial plexus anaesthesia. With this mixture anaesthesia was complete in $7 \frac{1}{2}$ minutes, and lasted for $7 \frac{1}{2}$ hours.

The basis for the behavior of the two new drugs is discussed, and it is concluded that they both fill a real but specialized clinical need.

\section{REFERENCES}

1. Löfgren, N. Studies on Local Anaesthesia: Xylocaine, a New Synthetic Drug. I. Haeggströms, Stockholm (1948).

2. Bromage, P. R. A Comparison of the Hydrochloride and Carbon Dioxide Salts of Lidocaine and Prilocaine in Epidural Analgesia. Acta anaesth. scandinav., Suppl. 16: 55 (1965).

3. Bromage, P. R.; Burfoot, M. F.; Croweld, D. E.; \& Truant, A. P. Quality of Epidural Blockade: III. Carbonated Local Anaesthetic Solutions. Brit. J. Anaesth. 39: 197 (1967).

4. Telivuo, L. A New Long-acting Local Anaesthetic for Pain Relief after Thoracotomy. Ann. chir. et gynaec. Fenniae. 52: 513 (1963).

5. Bromage, P. R. Spread of Analgesic Solution in the Epidural Space and the Site of Action: A Statistical Study. Brit. J. Anaesth. 34: 161 (1962).

6. EckmLom, L. \& WidMan, B. LAC-43 and Tetracaine in Spinal Anaesthesia: A Controlled Study. Acta anaesth. scandinav., Suppl. 23: 419 (1966).

7. Bromage, P. R. A Comparison of Bupivacaine and Tetracaine in Epidural Analgesia for Surgery. Canad. Anaesth. Soc. J. 16: 37 (1969).

8. Holmen, A. Axillary Plexus Block: A Double Blind Study of 59 Cases Using Mepivacaine and LAC-43. Acta anaesth. scandinav., Suppl. 21: 53 (1966). 